erected a chemical laboratory; it is intended for temporary use indeed, but affords facilities for school work almost rivalling those of the most costly appliances on Mr. Tuckwell's list, and at an expense not much greater than that of the cheapest ; in fact, it has been arranged on a plan based upon experience of the two schools in question. I have said it is intended for temporary use; I do not mean that it is not calculated for a fair term of serrice; it is temporary because the present location of the school is not a permanent one.

Abutting a stone wall to feet high, there is built a room 30 feet by 26 feet, and about 16 feet to the ridge of the roof; it is lighted by skylights on each slope of the roof, and the remainder of the roof is boarded and felted. The building is of timber, floor of wood, and about 9 inches above the ground. The bare building thus described cost 88l. The interior arrangements are as shown by the accompanying plan :-

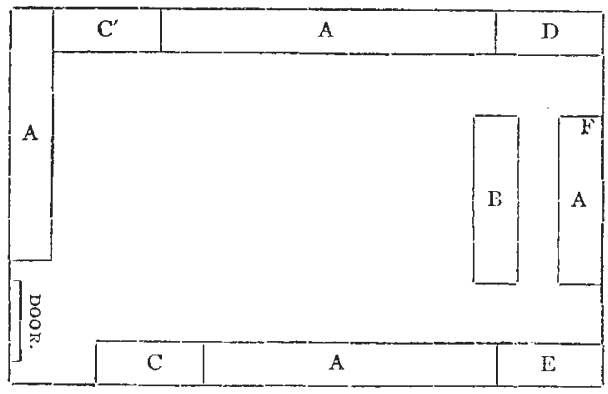

A A A are working-benches giving accommodation for a class of eighteen or twenty at practical chemistry.

They are of $\mathrm{I}_{\frac{1}{2}}$ inch deal, supported on tressels 33 inches above the floor and are 25 inches broad, with an under-bench for holding apparatus, and with three shelves in front of them; these are 6 to 9 inches deep, the lowest hold reagent bottles, the next exercises for analysis, and the top shelves are devoted to lecture apparatus when out of use. They are $14,30,48$ inches above the bench.

B, a lecture-table; its top is 12 feet long, 27 inches broad, $1 \frac{7}{2}$ inch thick, beneath are arranged drawers and shelves; it stands 3 feet above the ground. There are two supplies of gas, one about the centre of the table, fitted with three taps, to which Bunsen burners are at tached, another of much larger climensions, for supplying a combustion furnace, which does double duty, for warming in very cold weather "and lecture purposes at other times.

$\mathrm{C} \mathrm{C}^{\prime}$ are two slate sinks; $\mathrm{C}$ is 39 by $2 \mathrm{I}$ inches, and 6 inches deep, with three taps for water; $C^{\prime}$ is 32 by 2 I inches, and 6 inches deep, with two taps; the tops of the sinks are about 2 inches above the level of the workingbenches, and a third tap to $C^{\prime}$ serves to supply the condenser of a still.

$D$ is a fume closet $5 \mathrm{I}$ inches long, 23 inches deep, and 64 inches high; it is ventilated by a zinc flue about 6 feet high, under which a jet of gas is burnt when necessary; its doors are 4 feet high and glazed, and the roof slants back from the top of this to the wall.

$\mathrm{E}$ is a cupboard 48 inches long, 26 inches deep, 75 inches high, with glass doors; inside are shelves arranged for holding apparatus likely to be damaged by the atmosphere of the laboratory. This and the fume-closet are made fairly substantially of deal and are painted or stained. Except the front, back, and sides of the lecturetable, which also are stained and varnished, all other wood-twork is left bare.

Beneath $B$ is another cupboard of plain deal, for chemicals, \&c. ; it is 33 inches high measuring from the ground.

Gas is supplied to the working benches by I 7 jets from a $\mathrm{I}$-inch pipe, which is carried a few inches above the top of the bench round the room; the lecture-table, and a pendant with four burners for lighting purposes, are supplied by branches from this, and a third branch supplies the fume-closet.

There is a water-tap at $\mathrm{F}$ for lecture purposes, but no sink.

The cost of these fittings is as follows:-For gas and water fittings (the gas meter is a hired one), $21 l$. I $4 s .7 d$. ; for woodwork and sinks without water fittings, $5 \mathrm{I} l$. 3 s. $3 d$. They are all fairly substantially made, as it is intended to move them to the laboratory to be built at the new school. This sum includes lecturer's desk and stool, waste boxes, \&c. \&c.

The apparatus and chemicals include a Ruhmkorff coil by Apps, giving $\frac{3}{4}$ in. spark, combustion furnace, automatic copper-still, 8 lbs. mercury with suitable vessel for keeping it dry and "pure under oil of vitriol, Becker's balance turning to $\frac{1}{10}$ grain, ozone generator, Bunsen's cells, fourteen doz. stoppered reagent bottles, about six or eight doz. bottles for holding solids and solutions for analysis, two doz. 5-pint stoppered bottles for holding stocks of solutions, blowpipe with Fletcher's bellows; a supply of Bunsen's burners, test-tubes, racks, chemicals, and all the other indispensables of a laboratory.

These cost, including carriage by rail, \&c., somewhat under $47 l$., which sum will serve for our wants during the first six months' work.

The total cost amounts to 207l. 17s. Iod., to which we add about rol., not more, for some office expenses. For this sum we have a combined laboratory and lectureroom, which is calculated to be sufficiently capacious to afford instruction in theoretical chemistry to 70 per cent. of a school of 150 or 160 boys, and in practical chemistry to about 25 per cent. of the same number; also to serve as an occasional class-room for another science subject.

There is nothing handsome about this laboratory; externally it is tarred, and in summer it will be whitewashed; inside it is chiefly innocent of paint, and its walls are unplaned; but for real work there is very little wanting.

W. A. SHENSTONE

\section{A NEW DEEP-SEA THERMOMETER}

THE most efficient deep-sea thermometer constructed up to the present has been the one known as Six's thermometer, with the bulb protected from pressure, as invented by Messrs. Negretti and Zambra, and described in NATURE, vol. ix. p. 387 . This instrument has been extensively used by the expeditions sent out by various governments and scientific societies.

The disadvantages in the old instrument were the following:- $-\mathrm{I}$. The indices were, to a certain extent, unreliable, as, however carefully fitted, they were apt to slip down through their own weight, so that the observations were always more or less doubtful ; 2. Its accuracy, even in its most perfect condition, did not altain to fractions of a clegree, the closest readings differing at least half a degree; 3 . The instrument had always to be carried in a vertical position, or it would become consider. ably deranged. As long as it was sufficient to obtain temperatures varying not less than a degree from one another the old instrument answered tolerably well in deep seas. Recently, however, the bottom temperatures of shallow seas and rivers have come uncler investigation, and for that purpose the instru. ment proved unsuitable.

The difference between the temperature at the surface of the sea and that at the depth of a few fathoms does not amount to a whole degree, as a rule, but only to fractions of a degree; hence the observations, to be of any value at all, must be made with an undoubtedly accurate and delicate thermometer. The investigation of the temperatures of the British seas has been urged upon the Government by naturalists and physicists interested in the question of the food supply of the people in its relation to fisheries. The questions of greatest importance were those regarding the infuence of temperature upon the habits and migrations of fish, and the determination of the best seasons and temperatures for the development and capture of the various species. This investigation, commenced with the old instrument, has at present only shown that such instruments are not suffi. 
ciently reliable for the purpose; a new, more accurate, and more delicate instrument was therefore a great desideratum, and it seems that Messrs. Negretti and Zambra have now solved this problem in a satisfactory manner.

The construction of the new thermometer will be readily understood by reference to Fig. 3 . The bulb is cylindrical, and mercury is the thermometrical flud. The neck of the bulb is contracted in a peculiar manner at $\mathrm{A}$, and upon the shape and fineness of this contraction the succes: of the instrument mainly depends. Beyond $\mathrm{A}$ the tube is bent and a small catch reservoir is formed at $\mathrm{B}$, for a purpose to be presently explained. At the end of the tube a small receptacle $\mathrm{C}$ is provided. When the instrument is held bulb downwards it is seen to contain sufficient mercury to fill the bulb, tube, and a part of the reservoir c, leaving sufficient space in $\mathrm{C}$ for the expansion of the mercury when the temperature rises. In this position no scale would be possible, as the apparent movement of the mercury would be confined to the space $C$. When the thermometer is held bulb upwards the mercury breaks off at $\mathrm{A}$, but by its own weight flows down the tube, filling $\mathrm{C}$ and a portion of the tube above $\mathrm{C}_{9}$ this portion being in proportion to the existing temperature. The scale accordingly is divided from $\mathrm{C}$ upwards. To prepare the instrument for observation it is only necessary to place it bulb downwards, the mercury of course assuming the tempera. ture surrounding the instrument in the same way as any ordinary thermometer. When at any time or at any place it is required to read off the temperature, all that has to be done is to turn the thermometer bulb upwards, and to keep it in that position until the reading has been taken. This may be done at any time afterwards : for the quantity of mercury in the lower part of the stem which records the reading is too small to be appieciably influenced by a change of temperature, unless it be very considerable, while that in the bulb will continue to contract with greater cold and to expand with greater heat; and in the latter case some mercury will,pass the "contraction $A$ and may fall down and lodge at $i$, but it cannot go further as long as the bulb remains upwards; and thus the quantity recording the temperature in the stem will remain unaltered. It is seen, therefore, that this new instrument is simply a recording thermometer, which accurately and delicately records the tem perature at the time and place when and where it is turned over. It is not intended and cannot be used as a self-regis. tering maximum or minimum thermometer.

Of course some contrivance must be provided for turning the thermometer bulb upwards at any depth in the water. For this purpose the instrument is fitted into a wooden frame loaded with shot, free to move from end to end of it, and with its weight so regulated as to render the whole just buoyan in sea. water.

In using the thermometer a cord is passed through the hole in the frame nearest the bulb, and the instrument is fastened by this cord to the soundingline. In descending, the ther. mometer will be pulled down with the bulb downwards; but upon being pulled up, the in strument, owing to the resist ance offered by the water, will

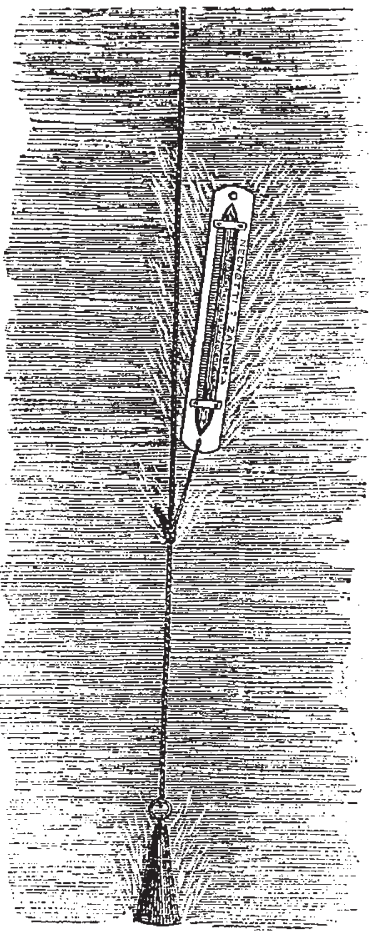

VIG. x,-Descending. indications would always be more or less faulty. Like an ordinary thermometer, it is devoid of air, and thus differs materially from Six's, which, containing compressed air, has a certain internal power of resistance. Hence the new instrument would be more affected by pressure than Six's, however thick the glass of the bulb. By the simple expedient of placing the entire thermometer into a glass shield or sheath, and hermetically sealing. the latter, the effect of external pressure is entirely eliminated. The shield must of course be a strong one. It need not be ex. hausted of air. Its effect, however, will undoubtedly be to render the thermometer it protects against pressure less sensitive towards changes of temperature; in other words, it will make it sluggish. To counteract this sluggishness, some mercury is introdnced into that portion of the shield which surrounds the bulb, and is confined there by means of a partition cemented in the shield round the neck of the thermometer bulb. The action of this mercury is that of a heat-conductor from the exterior of the shield to the interior of the thermometer, and the efficacy of this arrangement has been proved by experiment, the instrument thus protected being, in fact, far superior in sensitiveness to Six's thermometer.

As long as the shield withstands the pressure, the thermometer will be unaffected, and there is abundant evidence already to show that a shield of the above description will resist the pressure even at the bottom of the deepest ocean; doubtless it will be compressed a little at great depths, but the pressure will fail to have any appreciable effect upon the thermometer itself: This method of shielding is quite efficient, and thermometers thus protected need not be tested for pressure in the hydrauiic press; all that is necessary is to test them very accurately for sensitive ness and for errors of graduation. The new instrument is intended to be a stanclard instrument and permits the reading off of at least two-tenths or even one-tenth of a degree. The test for sensitiveness determines how many seconds the instrument requires

turn over and come up bulb uppermost; the temperature of the spot where it turned over will then be indicated. The illustrations we subjoin will further elucidate this matter.

As regards the thermometer itself, it was necessary, in order to make it perfectly accurate, to protect it against pressure, even if intended for shallow seas, as well as for the deepest. For whether used in deep or shallow water, unless so protected, its
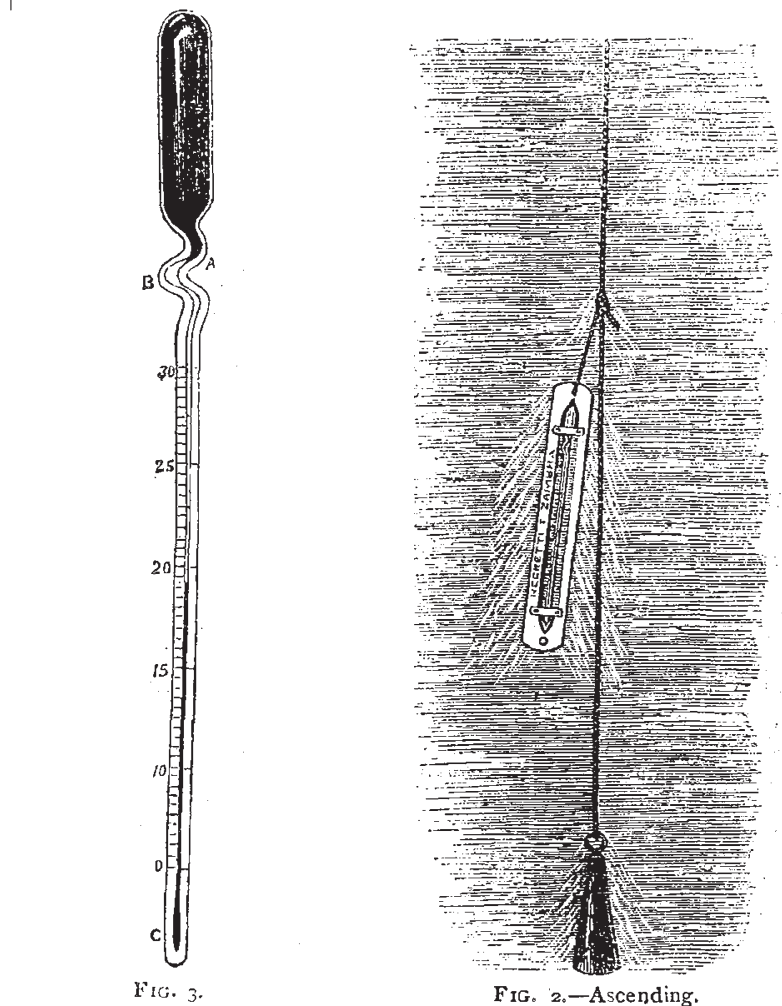

to note a change of $5^{\circ}$ rise or fall, and the time has been found to be from five to ten seconds.

A considerable number of these instruments have already been tested at Kew Observatory with perfectly satisfactory results, which place beyond doubt their value as standard deep-sea thermometers.

Thus, provided the turning-over gear is found to answer, this 
new instrument evidently possesses great advantages. It has no scale attached to it, the graduation and figures being distinctly marked on the stem itself, and the shield effectually preserves them from obliteration by sea-water. The back part of the stem is enamelled white, rendering the graduation and column of mercury extremely distinct.

When the instrument is immersed in the water the descending line may be stopped or checked any number of times, an 1 it is of course quite immaterial in what position the instrument enters the water; the illustrations show at a glance that it will infallibly assume the position "bulb downwards" when descending rapidly, and all that is needed is that care should be taken in the pulling upwards. The first pull in this direction should be quick and sudden and be continued for some little time; at the same time the pulling upwards must be continuous, since stoppages would invalidate the readings.

\section{UNIVERSITY AND EDUCATIONAL INTELLIGENCE}

A MEETING of the members of the Yorkshire College of Science was held on Monday at Leeds. A sum of $56,000 l$. has now been promised in donations, and the endowments from the Akroyd Foundation, the Clothworkers' Company, and the bequest of: the late:Mr. Brown would, if capitalised, represent a further sum of about $20,000 \%$. On the question of the proposed new university the committee reported that the college had held friendly communications with the authorities of Owens College, but could not at present make them the subject of a public report. Mr. Baines stated that the number of students this year was 355 , as compared with 288 last year.

We have received a calendar of the Newcastle College of Physical Science, which contains full information concerning the curriculnm at that institution, examination papers, scholarships, \&c.

\section{SCIENTIFIC SERIALS}

Bulletin de l'Academie Royale de Belgique, No. 4, I878.-In a further paper on the scintillation of stars, M. Montigny here deals with the changes of colour in stars of red and orange tints. From a table giving the general averages of relative frequency of the seven colours in such stars, it appears that the relative frequency of red much exceeds that of any of the other colours, whether in rainy or dry weather; that red, green, and especially orange, are in much greater proportion in dry than in rainy weather; while on the other hand, the frequency of blue and yellow is more marked under the influence of rain. Taking Pollux and Capella as samples of yellow stars, M. Montigny found in them the frequency of red and especially of yellow was much increased, while the proportion of orange was notably diminished. The proportion of blue was the same as in stars of the other type.-M. Masquelin contributes a valuable paper on the development of the inferior maxillar in man, in which he establishes the concurrence of the two modes of ossification in one bone, viz., that by the direct or metaplastic process, and that ly the indirect or osteoblastic. It would thus appear that the histo. logical process of ossification cannot serve to determine the morphological value of a bone, - A paper on oscillations of the Belgian coast, by $M$. Van Rysselberghe, aims at proving a sinking of the coast at Ostend, but the validity of the evidence is doubted by the reporters.-An interesting repoit on Daltonism in relation to railway-working is presented by $M$. Delbœuf.-M. Fraipont has a fourth and concluding article on the Acetinians of the Ostend coast, and Dr. Woodward records the discovery of a species of Brachyour crustacean in the coal formation near Mons (to which his attention was called by M. de Koninck). - The theory of the telephone is the subject of a note by MM. Navez.

Fournal de Physique, May, I878.-A new spectroscope here described by $M$. Thollon offers several advantages; it is direct vision and of perfect symmetry, and can be easily adapted to astronomical telescopes; the prisms (movable) are worked by a rigorously geometrical process, so that a ray coming along the axis of the collimator reaches the axis of the telescope only after twice traversing the whole system of prisms with the minimum of deviation; a considerable dispersive power may be had and may be widely modified in the same instrument; lastly, it affords very exact spectrometric measurements.-Some experiments in which the electro-magnetic rotation of liquids is illustrated with acidulated water containing a little lycopodium powder, the effect being projected by means of Duboscq's new apparatus, are described by M. Bertin. M. Gernez has a nnte on the production of different hydrates in concentrated supersaturated solutions under the influence of a mechanical action (rubbing the walls of the vessel with a rigid rod). - The metallic reflection of polarised obscure calorific rays is studied by M. Mouton.

Reale Istituto Lombardo di Scienze è Lettere, Rendiconti, vol, xi fasc. vii. - We note the following papers in this number :-Jealous insanity, by M. Verga. - Expression of pain according to sex, age, individual constitution, and race, by M. Mantegazza. - Contribu tions to the study of the Italian chiroptera, by M. Regalia.-On the cranium of Volta, by M. Lombrosi.-Examination of the observations made by the committee appointed to adjudicate a prize on the theme, "Programme of a Hospital for Contagious Diseases, suited to the City of Milan," by M. Zucchi. - Study on the prevalent diseases of the vine, by MM. Garovaglio and Cattaneo.

Vol. $x i_{\text {, }}$ fasc. viii., ix.-In these numbers we note the fol Iowing :-On dominant diseases of vines, by MM. Garovaglio and Cattaneo.-Studies on the albumen of milk and on the origin of buttermilk curd, by MM. Musso and Menozzi.--On the canses and circumstances affecting hereditary transmission in animals, by $M$.. Lemoigne.-Observations on elephantiasis in the Arabs in the environs of the Ticinese district, by M. Sangalli. - The third molar in the human race, by $M$. Mantegazza.-On the distribution and termination of nerves in the tendons of man and other vertebrata, by M. Golgi.

Zcitschrift fïr wissenschaflliche Zoologie, vol. xxx., supplement, part I. - On the form of the crystalline cones in arthropod eyes, especially phronima, by Oscar Schmidt.-On anomia, with remarks on the muscular system of lamellibranchs, by $\mathrm{H}$. von Jhering.-The poison apparatus of ants, by A. Forel, $4 \mathbf{r}$ pp. two plates. - The post-embryonic formation of limbs in insects, by $H$. Dewitz, dealing especially with formica, $28 \mathrm{pp}$.-Contribution to the structure and development of the lungs in mammals, by Ludwig Stieda; figures from embryonic sheep, mouse, and horse.- On the ornamental colouring of Daphnidæ, by August Weismann. The author believes the colour patterns are secondary sexual characters developed by sexual selection. On the action of the voluntary muscles in land snails, by $\mathrm{H}$. Simroth.

Vol. xxxi., part 3.-Researches on the structure and development of sponges, part 4, by F. E. Schulze; 42 pp., fous plates. This part deals especially with the family Aplysiadæ. -Contribution to the development of feathers, by Dr. Th. Studer, Professor at Berne; the feathers of the Penguin, Megapodius, and Dromxus, are dealt with and figured in two plates.-On the fertilisation of the eyg in Petromyzon planeri, by Ernst Calberla, with a discussion on fertilisation generally; 50 pp., two plates.-On the formation of ova, and on the male of Bonellia viridis, by Franz Vejdovsky.

Fournal of the Russian Chemical and Physical Societies of St. Petersburg (vol. $x$. No. 4) contains the following papers:On the action of peroxide of hydrogen upon the oxygen compounds of thallium, by $\mathrm{E}$. Schöne.-On the action of iodine upon certain urea and amidogen compounds, by W. Roudneff.On nitrophthalic and oxyphthalic acids, by O. Miller.-On the admixture of zine in different parts of the body after the intoxication with acetate of zinc, by M. Mazkewicz.-On the action of water and oxide of lead on the halogen compounds of ethylene hydrocarbons, by A. Eltekoff.-On the action of the same substances upon bromide of diamylene, by the same.-On the action of trichlorolactic acid upon urea, by D. Cech.-On the magnetic induction of the two spheres, by $\mathrm{O}$. Chwolson.

\section{SOCIETIES AND ACADEMIES LONDON}

Geological Society, June 19.- John Evans, D.C.L., F.R.S., vice-president, in the chair.-Charles Louis Buxton, Wybrandts G. Olpherts, and William Phelps Richards were elected Fellows of the Society.-The following communications were read :-On the section of Messrs. Meux and Co.'s artesian well in the Tottenham Court Road, with notices of the well at Crossness, and another at Shoreham, Kent; and on the probable range of the lower greensand and palzozoic recks moder 